\title{
ActiTrainer-determined segmented moderate-to-vigorous physical activity patterns among normal-weight and overweight-to-obese Czech schoolchildren
}

\author{
Erik Sigmund • Dagmar Sigmundová • Romana Šnoblová • \\ Andrea Madarásová Gecková
}

Received: 6 June 2013 / Accepted: 10 September 2013 / Published online: 24 September 2013

(C) The Author(s) 2013. This article is published with open access at Springerlink.com

\begin{abstract}
This study uncovered the patterns of moderate-tovigorous physical activity (MVPA) in normal-weight and overweight/obese children before, during, and after school lessons. ActiTrainer-based MVPA was assessed over 2 school days (with and without a physical education lesson [PEL] in a sample of three hundred thirty-eight 9- to 11-year-old children (50.3\% female; $29.6 \%$ overweight/obese), in the Czech Republic, during spring 2012. MVPA was quantified based on the step count (number), MVPA duration, and MVPA heart-rate response (minutes). No differences in the MVPA based on the time during the school day were confirmed in normal-weight versus overweight/obese girls, whereas normal-weight boys significantly exceed their overweight/obese peers in step count and afterschool and daylong MVPA. Active participation in PEL contributes to a significantly higher step count, exercise duration, and MVPA heart-rate response in normal-weight and overweight/ obese boys $(p<0.001)$ and normal-weight $(p<0.001)$ and overweight/obese $(p<0.04)$ girls during school time. Moreover, active participation in PEL significantly $(p<0.04)$ increases the overall daily step count, duration, and MVPA heart-rate response in normal-weight boys and overweight/obese girls. Active exercise during PEL accounted for $16.7 \%$ of the total number of
\end{abstract}

\section{E. Sigmund · D. Sigmundová • R. Šnoblová • A. M. Gecková Center for Kinanthropology Research, Faculty of Physical Culture, Palacky University, Olomouc, Czech Republic}

\section{A. M. Gecková}

Health Psychology Unit, Institute of Public Health, Faculty of Medicine, P.J. Safarik University in Kosice, Kosice, Slovak Republic

\section{A. M. Gecková}

Olomouc University Social Health Institute (OUSHI),

Palacky University, Olomouc, Czech Republic

\section{E. Sigmund $(\bowtie)$}

Faculty of Physical Culture, Palacky University, Třída Míru 115,

77111 Olomouc, Czech Republic

e-mail: erik.sigmund@upol.cz steps, $25.1 \%$ of overall MVPA duration, and $24.1 \%$ of the MVPA heart-rate response in 9- to 11-year-old children. During days with a PEL, a significantly $(p<0.02)$ higher number of overweight/obese girls and a higher number of normal-weight boys achieved the duration of $60 \mathrm{~min} /$ day of MVPA compared with days without a PEL. Conclusion: Adding one PEL or an equivalent amount of MVPA to the daily school routine appears to be a promising strategy to effectively increase daily MVPA, particularly among overweight/obese girls.

Keywords Obesity $\cdot$ Physical education $\cdot$ School $\cdot$ Steps · Heart-rate response

\section{Introduction}

The increase in child obesity has been reported by the World Health Organisation (WHO), which argued that the proportion of overweight and obese children in the European countries is still increasing [9]. In Czech Republic, an increasing trend was found in the proportion of overweight or obese schoolchildren [51, 61]. While the proportion of overweight or obese girls ranged from $11-16 \%$ in 2010 , overweight or obesity in boys ranged from $22 \%$ to $31 \%$ [51].

Although the worldwide prevalence of childhood obesity has considerably increased during the past three decades [31, $41,42]$, and a decrease in objectively measured physical activity (PA) in children has been documented $[24,50]$, effective obesity-reducing public health interventions and strategies are still limited. Specific causes of obesity are, at a population level, consistent with a long-term positive energy balance that could be a result of a low level of daily PA and prevailing sedentary behaviour [6,52]. With respect to the fact that physical activity in childhood influences physical activity in adulthood [53], it is tracked well from childhood to adulthood [25] similar to body mass index (BMI). The enhancement of physical activity in 
children is of great importance for the promotion of public health [25]. Effective obesity-reduction interventions in children may need to incorporate moderate-to-vigorous physical activity (MVPA) [52] to permanently increase the level of daily PA [49].

Schools, where children spend as much as a half of their day, offer an optimal environment for designing, implementing, and evaluating behavioural interventions to prevent and reduce excessive weight gain in children and adolescents, independent of their race, gender and socio-economic family status [28, 32, 35]. School-based interventions can not only increase MVPA and reduce the prevalence of overweight/obese preadolescent children $[28,49]$ but also improve their fitness [28, 34, 44]. Moreover, the contribution of long-term active participation in physical education lessons (PEL) to overall school-day MVPA and fitness in preadolescent children has been highlighted [28, 44]. Theoretically, schools offer to all school-aged children the same environmental stimuli to be physically active, but in reality, MVPA is extremely variable among individuals on different school days and different times in the school day [21].

However, little is known about the MVPA patterns in normal-weight and overweight/obese boys and girls during different segments of the school day (before school lessons, during PEL and other lessons, recesses, and after school). Given that the number of global and national health-promoting PA recommendations has increased considerably during the past few years [14, 15, 27, 55], determining which segments of the school day may benefit from strategies to reduce sedentary behaviour and increase MVPA is extremely important. To understand when and how much PA children have during the school day, the objective, field-based measurement of MVPA is mandatory [6, 64], especially for obese children [43].

Pedometers provide a reasonable assessment of a child's daylong PA [37] and PA during a certain segment of the school day $[10,58]$. However, pedometers are used only when the total amount of PA is of interest [48]. Accelerometers enable a higher precision and accuracy than pedometers $[1$, $7,47,48]$ and allow an objective analysis of the frequency, intensity, and duration of PA during various segments of the day with minimal interference in daily life [47]. Heart-rate monitoring is considered a valid and reliable method for assessing PA over extended time periods [4] but is an indirect measure that indicates the relative stress placed upon the pulmonary system by PA $[2,3]$. The limitations associated with heart-rate monitoring are primarily caused by biological variance, while the limitations associated with accelerometers are predominantly biomechanical [8]. Considering the fact that the errors related to heart-rate and accelerometer PA monitoring are independent, combining the two techniques may provide a more accurate assessment of PA than either technique alone [7, 48]. Previous studies have revealed the contribution of MVPA during school recesses to overall daily PA in overweight and non-overweight children; however, the advantages and disadvantages of combining heart-rate and accelerometer PA monitoring have not been discussed [23]. Moreover, the MVPA patterns in normal-weight and overweight/obese children during other segments of the school day (before school lessons, during PEL, and after school leisure time) using heart-rate and accelerometer-based PA monitoring remain unclear.

This study assessed the MVPA patterns in 9- to 11-year-old normal-weight and overweight/obese boys and girls during different segments of the school day (before school lessons, during PEL and other lessons, recesses, and after school) using different MVPA indicators (accelerometer-based step count, MVPA duration, and MVPA heart-rate response). The specific objectives were the following:

(1) To describe the differences in MVPA during specific segments of the school day (before school, during PEL and other lessons, recesses, and after school) in normalweight and overweight/obese girls and boys.

(2) To quantify the contribution of active participation in PEL to the overall daily MVPA in normal-weight and overweight/obese girls and boys.

(3) To examine the achievement of the current recommendations for MVPA duration during a school day with active participation in a PEL in normal-weight and overweight/obese girls and boys.

\section{Methodology}

Sample

The research included a total of six elementary schools, one from a city of over 100,000 inhabitants - Olomouc, four schools from smaller towns of 5,000-30,000 inhabitants Hranice na Moravě, Staré Město u Uherského Hradiště, Polička, Rýmařov and one school from a village of Lutín with less than 4,000 inhabitants. The schools are located in four regions out of 14 regions in the Czech Republic: Pardubice Region, Olomouc Region, Zlín Region and Moravian-Silesian Region. The selection of schools corresponded with the distribution of urban-rural population in the Czech Republic [13]. The convenience sample of all six elementary schools was based upon uniformly implemented mandatory daily school routines (described below), similar size, similar available sports and equipment (one large gymnasium, one smaller dancing hall with a fitness section and an outdoor field), and a similar number of students (450-650). All third and fourth grades students from the selected schools were included in the study. Children entering grade 3 are 8-9 years old, and children entering grade 4 are aged $9-10$ years. After a detailed presentation of the study by the administrator, 365 children (187 girls and 178 boys) aged 9-11 years started 3-day monitoring of 
overall daily PA during the morning hours. The measurement on the first day was excluded from the data analysis because this recording was incomplete and the novelty of wearing the ActiTrainer device could have affected the initial activity (reactivity). The school routine on one of the 2 monitored days included one 45-min PEL. The final, accelerometer-based, 2-day PA monitoring was completed, and a total of 338 children (170 girls and 168 boys) with a median age of 9.91 (range $9.34-10.50)$ years $(29.6 \%$ overweight/obese) were included in the data analysis. Absence from all segments of the school routine or non-active participation in the PEL constituted a reason for excluding ten and 17 children, respectively (representing $8 \%$ of the girls and $6.7 \%$ of the boys). All assessed children wore the ActiTrainer accelerometer continuously for 2 days (excluding sleeping, hygiene, and bathing times) for a minimum of $12 \mathrm{~h} /$ day. The accelerometer-based 2day monitoring for overall daily PA was conducted for a median value of 14.37 (range 12.31-16.36) h daily.

Between Tuesdays and Thursdays in April and May 2012, all participating children followed a mandatory daily school routine, including five school lessons, three short recesses, one longer recess, and one lunchtime break. School lessons started at 8:00 $\mathrm{Am}$, and all of them lasted $45 \mathrm{~min}$ and finished at 12:15 PM. On one of the monitored days, all of the children participated in one 45-min PEL with similar movement games (e.g., tag, simplified versions of dodgeball/floorball) and exercises with equipment (e.g., ball dribbling, catching, throwing at a target, jump rope, small trampoline jumping) in the gym. One of the four school recesses lasted $20 \mathrm{~min}$, while the others were 5 min long. During the 20-min recess, the children were allowed to eat their own snacks or to play in their classroom under teacher supervision. The lunchtime break started at 12:15 PM and finished between 12:45 and 13:00 PM. After lunch, the children left school or stayed in an after-school program. Because not all of the children stayed in the after-school program, the time spent in the after-school program was not included in the time for the daily school routine.

\section{Instruments and measurements}

The ActiTrainer (ActiTrainer ${ }^{\mathrm{TM}}$, Florida, USA) is a small, light $(8.6 \times 3.3 \times 1.5 \mathrm{~cm} ; 53 \mathrm{~g})$ multi-functional device. The ActiTrainer consists of a heart-rate monitor, tri-axis solid-state accelerometer, electronic pedometer, inclinometer, and ambient light sensor. Data recording can be viewed on a built-in display; however, the display was covered during monitoring. When turned on, the ActiTrainer can monitor and continually store recorded data over a period of 7 days. The validity and reliability of the ActiTrainer-based step counting in nonlaboratory conditions has been verified with 20 non-obese university students [39], and the feasibility of assessing PA patterns in children has been verified in 2-day monitoring of 9to 10-year-old Polish girls and boys [23].
The ActiTrainer accelerometer was positioned around the waist above the right knee and continuously measured MVPA in the children at 15-s intervals for the entire body-wearing time. When monitoring MVPA, the ActiTrainer was secured at the waist using a neoprene pouch and an elastic belt. When collecting the heart-rate data, a Polar chest belt Wearlink T31 (Polar Electro Inc., New York, NY, USA) was worn across the sternum. The measured MVPA was simultaneously represented by three indicators - accelerometer-based step count (number), MVPA duration (minutes), and MVPA heart-rate response (minutes). In line with previous recommendations [46], a daily step count less than 1,000 or greater than 30,000 was considered to be incorrect and was discarded. The daily accelerometer count was used as a measure of MVPA duration, and cut-off points for MVPA were defined as greater than 574 counts per $15 \mathrm{~s}$ based on published recommendations [56]. The MVPA heart-rate response was set based on the percentage of the maximum age-related heart rate (i.e., 220age) [17]. A MVPA heart-rate response was defined as a heart rate above $60 \%$ of the maximum age-related heart rate in accordance with published studies [17,33].

One week before the start of monitoring, the parents were asked to provide information about the body height and weight of their children within $0.5-\mathrm{cm}$ and $0.1-\mathrm{kg}$ accuracies. The calendar age was calculated from the date of birth until the first monitoring day. The BMI $\left(\mathrm{kg} / \mathrm{m}^{2}\right)$ was calculated as the body weight $(\mathrm{kg})$ divided by the body height $(\mathrm{m})$ squared. Obesity and overweight and normal body mass were classified using percentile BMI charts for girls and boys aged 5 to 19 [62], where overweight and obesity represented the 85-97 and $>97$ percentiles, respectively, on age-differentiated BMI charts available on the WHO website [62].

After completing morning hygiene routines on the first monitored day, the parents of the participating children fastened the Polar chest strap around their child's chest and attached the elastic waist belt with the ActiTrainer tightly to their right hip. After arriving at school, the first, second or third author of the study and the teacher checked the functioning of the ActiTrainer and wrote down the time of arrival in the proxy report. The proxy report included the chronological structure of the day according to the current school schedule to record the time of morning attachment of the device, arrival at school, beginnings and ends of lessons and recesses, departure from school and evening removal of the device. Under the supervision of their class teachers, the participating children further recorded the beginning times of the school lessons and recesses in the proxy report. In the evening, the parents recorded the time when both elastic belts were removed.

Statistical analysis

The data were analysed using SPSS v19.0 software (IBM SPSS, Inc., Chicago, IL, USA) and STATISTICA v.9 (StatSoft, 
Czech Republic). The data were analysed in total for all classes because the TwoStep cluster analysis found no indicator for clustering by school. A series of the non-parametric MannWhitney U-test were conducted to determine differences in the dependent variables (before school, during PEL and other lessons, recesses, and after-school time) and accelerometerbased MVPA indicators (step counts, duration, and heart-rate response) in the normal-weight and overweight/obese girls and boys. A comparison of BMI in the normal-weight and overweight/obese children was performed using the nonparametric Mann-Whitney $U$-test. The Wilcoxon pair test was repeatedly used to examine the differences in the MVPA indicators (before school, during school, after school and all day) on school days with and without a PEL between the normal-weight and overweight/obese boys and girls. The Wilcoxon pair test was used to examine whether the normalweight and overweight/obese boys and girls met the current recommendations for MVPA duration on the school days with active participation in a PEL compared to the day without a PEL. The strength of the relationship between the independent (MVPA indicators in normal weight and overweight/obese girls and boys) and dependent variables (segments of the school day) was assessed using the effect size $d$ coefficient for the MannWhitney and Wilcoxon pair tests $[11,12]$. The $d$ values of 0.2 , 0.5 and 0.8 may be interpreted as small, medium and large effects [54].

\section{Ethics}

The study was approved by the Ethical Committee of the Faculty of Physical Culture, Palacky University, Olomouc. The children's parents, their teachers and school management representatives were informed of the objectives of this descriptive research survey. Free and voluntary participation of the children in this study was documented using a written approval form signed by their parents.

\section{Results}

In total, 170 girls and 168 boys were eligible for this analysis. The median (full ranges) values of the children's anthropometric characteristics and MVPA indicators during the school day are presented in Table 1. Among all participating children, $24.7 \%$ of the girls and $34.5 \%$ of the boys were classified as overweight or obese. Unlike the boys, there were no significant differences in the accelerometer-based step count (number), MVPA duration (minutes), or MVPA heart-rate response (minutes) between the normal-weight and overweight/obese girls in any of the compared segments of the school day (Table 1). The normal-weight girls did not significantly differ from their overweight/obese classmates in any of the MVPA indicators during the school day. The normal-weight boys had a significantly higher step count and MVPA duration over the entire day compared to the overweight/obese boys, but there were no significant differences in any of the other school time subcomponents.

In terms of the contribution of active participation during the PEL to overall daily MVPA in the children, the values were $15.9 \%\left(15.4 \%, 16.3 \%_{\gamma}\right)$ of the daily step count, $23.0 \%(21.8 \%$, $24.2 \%)$ of the daily MVPA duration, and $21.5 \%(19.6 \%$, $23.4 \%)$ of the daily MVPA heart-rate response. Active exercise during the PEL amounted to $15.6 \%$ of the normal-weight $(15.8 \%$ \% $15.4 \%$ ₹ $)$ and $16.4 \%$ of the overweight/obese $(14.2 \%$ \% $18.1 \%$ ) children for the overall daily step count, $22.5 \%$ of the normal-weight $(22.4 \%$, $22.6 \%$ ) and $24.1 \%$ of the overweight/obese (20.1\%o $27.0 \%$ ) children for the overall daily MVPA duration, and $21.0 \%$ of the normal-weight $(19.7 \%$ \% $22.5 \%$ ) and $22.7 \%$ of the overweight/obese $(19.2 \%$, $25.2 \%$ ) children for the overall daily MVPA heart-rate response.

Active participation in the PEL led to significantly higher school MVPA in the normal-weight and overweight/obese girls and boys (Fig. 1) compared to the school days without a PEL. Participation in the PEL led to a significantly higher overall daily MVPA compared to the day without a PEL for the overweight/obese girls (step count $p \leq 0.05, d=0.67$; MVPA duration $p \leq 0.05, d=0.64$; heart-rate response $p \leq 0.001$, $d=0.98$ ) and normal-weight boys (step count $p \leq 0.001$, $d=0.66$; MVPA duration $p \leq 0.001, d=0.65$; heart-rate response $p \leq 0.05, d=0.46$ ).

During the school day with active participation in a PEL, a significantly $(p<0.02)$ higher percentage of overweight/obese girls $(+33.3 ; 47.6 \%$ vs. $14.3 \%)$ and significantly $(p=0.1)$ higher percentage of normal-weight boys $(+16.4 ; 47.3 \%$ vs. $30.9 \%$ ) achieved the recommended duration of $60 \mathrm{~min}$ MVPA/day [14, 15, 27, 62] than on the school day without a PEL. Similarly, a higher percentage of normal-weight girls (+3.1; $23.4 \%$ vs. $20.3 \%)$ and overweight/obese boys (+3.5; $20.7 \%$ vs. $17.2 \%$ ) reached 60 min of MVPA on the school day with a PEL compared to the school day without a PEL, but these differences were not significant.

\section{Discussion}

The main aim of this study was to assess the patterns of accelerometer-based school day MVPA in normal-weight and overweight/obese school-aged children evaluated by three simultaneously monitored MVPA indicators - step count, MVPA duration, and MVPA heart-rate response. The most salient aspect of this innovative MVPA monitoring during the different segments of the school day was identifying distinctly similar MVPA patterns in each of the above-mentioned indicators. The findings of this study enrich previous valuable publications $[6,10,21-23]$ by providing a detailed analysis of gender 
Table 1 Anthropometric characteristics and indicators of accelerometer-based MVPA during 2-day monitoring (median (full ranges)) of 9- and 11-yearold overweight/obese and normal-weight children

\begin{tabular}{|c|c|c|c|c|c|c|}
\hline & \multicolumn{3}{|l|}{ Girls $(n=170)$} & \multicolumn{3}{|l|}{ Boys $(n=168)$} \\
\hline & Normal-weight $(n=128)$ & $d$ & Overweight/obese $(n=42)$ & Normal-weight $(n=110)$ & $d$ & Overweight/obese $(n=58)$ \\
\hline \multicolumn{7}{|l|}{ Anthropometric data } \\
\hline Age (years) & $9.84(11.18-8.69)$ & 0.29 & $9.41(11.21-8.58)$ & 9.99 (11.28-8.67) & 0.09 & $10.04(11.12-8.87)$ \\
\hline Body height $(\mathrm{cm})$ & $140.50(159.00-125.00)$ & 0.08 & $142.00(150.00-131.00)$ & $142.00(159.00-128.00)$ & 0.56 & $148.00(160.00-127.00)^{* * *}$ \\
\hline Body weight (kg) & $31.00(43.00-22.00)$ & 1.33 & $43.00(52.00-34.00)^{* * *}$ & $32.00(45.00-22.00)$ & 1.39 & $46.00(70.00-30.00)^{* * *}$ \\
\hline BMI $\left(\mathrm{kg} / \mathrm{m}^{2}\right)$ & $15.79(19.63-12.25)$ & 1.48 & $21.22(24.06-18.77)^{* * *}$ & $15.87(18.88-13.20)$ & 1.62 & $20.41(27.34-16.86)^{* * *}$ \\
\hline \multicolumn{7}{|c|}{ Step count - (number) } \\
\hline Before school & $806(3,052-17)$ & 0.11 & $906(2,740-21)$ & $810(3,153-22)$ & 0.24 & $1,021(2,387-73)$ \\
\hline At school & $2,240(6,392-511)$ & 0.01 & $2,209(6,653-968)$ & $2,969(8,691-669)$ & 0.18 & $2,585(6,924-729)$ \\
\hline PEL & $1,590(2,759-615)$ & 0.11 & $1,538(2,447-805)$ & $1,590(3,212-803)$ & 0.14 & $1,505(2,920-785)$ \\
\hline Other lessons & $632(3,374-230)$ & 0.25 & $815(4,183-190)$ & $825(5,314-228)$ & 0.12 & $740(4,882-248)$ \\
\hline Recesses & $743(2,449-108)$ & 0.07 & $712(2,741-289)$ & $981(5,323-221)$ & 0.10 & $871(2,226-243)$ \\
\hline After school & $6,203(17,574-729)$ & 0.08 & $6,161(9,623-1,594)$ & $6,161(16,102-662)$ & 0.30 & $5,729(13,125-725)$ \\
\hline All day & $9,738(20,559-1,816)$ & 0.01 & $9,872(13,750-3,970)$ & $10,629(23,663-3,829)$ & 0.32 & $9,430(18,257-3,579)^{*}$ \\
\hline \multicolumn{7}{|c|}{ Duration of MVPA - time $>2,296$ counts/min (min) } \\
\hline Before school & $1.50(18.75-0.00)$ & 0.25 & $2.55(19.50-0.07)$ & $2.00(24.75-0.00)$ & 0.06 & $2.32(15.75-0.07)$ \\
\hline At school & $10.00(73.18-2.16)$ & 0.08 & $11.65(31.45-1.91)$ & $14.32(63.34-1.95)$ & 0.24 & $9.15(39.75-1.91)$ \\
\hline PEL & $9.95(19.00-0.75)$ & 0.04 & $9.95(20.00-1.25)$ & $10.12(31.25-4.50)$ & 0.11 & $9.95(21.00-0.00)$ \\
\hline Other lessons & $2.30(21.75-0.50)$ & 0.02 & $1.84(15.00-0.82)$ & $3.00(33.75-0.50)$ & 0.21 & $1.97(22.50-0.75)$ \\
\hline Recesses & $2.75(59.80-0.50)$ & 0.09 & $3.00(15.00-0.00)$ & $3.54(31.25-0.50)$ & 0.21 & $2.72(27.25-0.82)$ \\
\hline After school & $26.89(85.72-0.00)$ & 0.10 & $25.96(115.84-0.00)$ & $31.40(104.74-0.00)$ & 0.40 & $16.83(134.31-0.40)^{*}$ \\
\hline All day & $42.90(112.23-5.49)$ & 0.12 & $43.42(139.58-8.91)$ & $52.42(129.85-7.92)$ & 0.45 & $34.68(162.90-7.64)^{* *}$ \\
\hline \multicolumn{7}{|c|}{ Heart-rate response - time $>60 \%$ of the maximal age-related heart rate (min) } \\
\hline Before school & $4.50(60.26-0.00)$ & 0.20 & $8.71(37.79-0.00)$ & $2.25(42.24-0.00)$ & 0.02 & $3.12(37.50-0.00)$ \\
\hline At school & $13.86(114.25-0.00)$ & 0.14 & $19.00(122.50-0.00)$ & $23.75(214.00-0.00)$ & 0.23 & $13.48(136.25-0.00)$ \\
\hline PEL & $16.25(41.75-0.00)$ & 0.15 & $18.50(38.75-0.00)$ & $20.25(44.25-0.00)$ & 0.02 & $16.75(42.00-0.00)$ \\
\hline Other lessons & $2.38(87.50-0.00)$ & 0.29 & $5.00(68.25-0.00)$ & $3.88(90.00-0.00)$ & 0.27 & $1.75(67.75-0.00)$ \\
\hline Recesses & $3.25(52.75-0.00)$ & 0.16 & $3.88(38.50-0.00)$ & $5.25(79.75-0.00)$ & 0.04 & $4.50(32.50-0.00)$ \\
\hline After school & $46.60(313.74-0.00)$ & 0.30 & $66.71(344.88-0.00)^{*}$ & $33.96(332.28-0.00)$ & 0.02 & $20.19(289.30-0.00)$ \\
\hline All day & $82.61(383.44-6.25)$ & 0.32 & $120.42(465.67-16.68)^{*}$ & 73.87 (334.93-0.49) & 0.08 & $54.45(355.25-2.50)$ \\
\hline
\end{tabular}

$n$ number of participants, $B M I$ body mass index, $P E L$ physical education lesson, $M V P A$ moderate-to-vigorous physical activity, $d$ effect size coefficients for the Mann-Whitney test

Statistical significance (Mann-Whitney test) for the differences between the overweight/obese and normal-weight children in anthropometric variables is expressed as: ${ }^{*} p<0.05, * * p<0.005, * * * p<0.001$

and body mass differences in step count, MVPA duration, and heart-rate response during specific segments of the school day.

Regarding the first specific objective of the present study, we found different MVPA patterns between the school segments and after school for the different genders and body mass levels. Contrary to the results of previous studies $[6,22,36$, 43, 45], we did not find significantly less MVPA in girls than age-matched boys. The comparable level of school and daylong MVPA in the girls and boys was probably caused by the same school routine and the fact that Czech adolescent boys spend more time using the computer in their leisure time than girls [30, 50]. Moreover, the MVPA patterns for the normal- weight and overweight/obese children during school were also similar for all of the analysed indicators. However, other studies using pedometers [10, 38] and accelerometers [43] point to higher daily step counts and MVPA times for the normal-weight children of both genders than the overweight/ obese boys and girls. Our findings are unexpected but encouraging and validate the previous requirement for all participating children to have a daily school routine that includes five school lessons, three short recesses, one longer recess, and one lunch-time break.

Nevertheless, significant differences in the MVPA duration between the normal-weight boys and overweight boys were 
Fig. 1 Comparison of school day moderate-to-vigorous physical activity in children between a day with active participation in a PEL and a day without a PEL.

$n$ number of participants, $P E L$ physical education lesson, $M V P A$ moderate-to-vigorous physical activity, \# values less than $4.5 \mathrm{~min}$ Statistical significance (Wilcoxon pair test) of the differences between the groups of normalweight and overweight/obese children in moderate-to-vigorous physical activity indicators in a day with and without PEL is expressed as: ${ }^{*} p<0.04,{ }^{* *} p<0.01$ $* * * p<0.001$
GIRLS - normal-weight ( $n=64)$ and overweigth/obese $(n=21)$

Step counts (number)

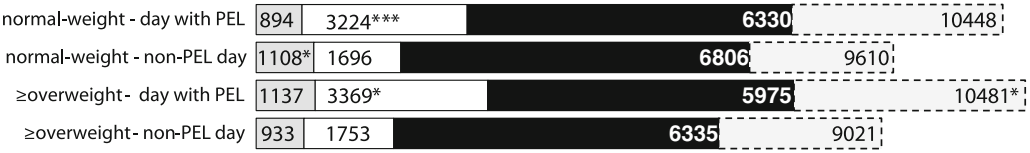

MVPA Duration (minutes)

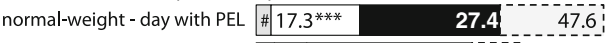

normal-weight - non-PEL day $\# 6.3$

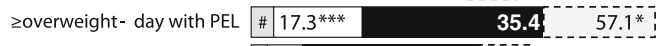

zoverweight- non-PEL day \#6.9 $\quad \mathbf{3 4 . 4} 44.5$ !

Heart-rate response (minutes)

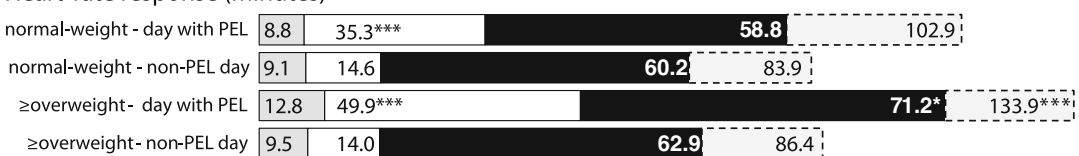

BOYS - normal-weight $(n=55)$ and overweight/obese $(n=29)$

Step counts (number)

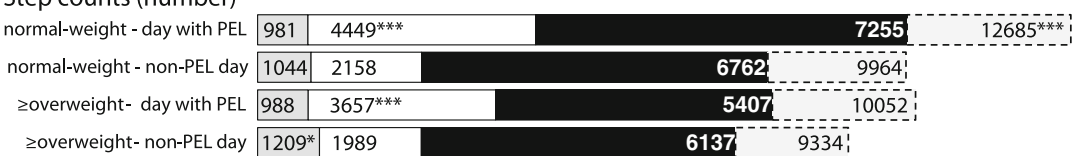

\begin{tabular}{ll|l|l|l} 
zoverweight- non-PEL day & $1209^{*}$ & 1989 & $\mathbf{6 1 3 7}$ \\
\hline
\end{tabular}

MVPA Duration (minutes)

normal-weight - day with PEL \#23.8*** $\quad$ 27.4 $63.1 * *$.

normal-weight - non-PEL day \#9.2 $\quad 34.2$

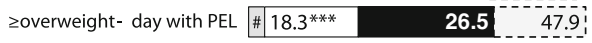

zoverweight- non-PEL day \# $7.9 \quad 25.0$

Heart-rate response (minutes)

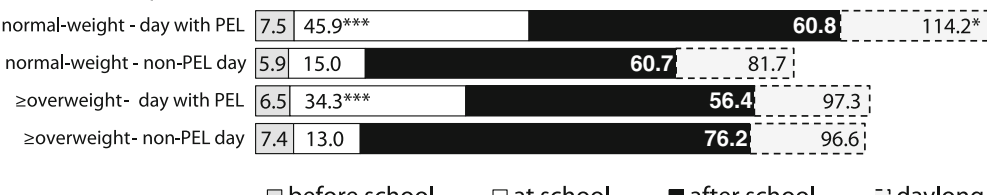

$\square$ before school $\quad \square$ at school $\quad$ after school daylong found in after-school and day-long measurements. The normal-weight boys tended to be more physically active than the overweight/obese boys, unlike their female classmates. However, interpreting the differences in MVPA between the normal-weight and overweight/obese children according to the ActiTrainer data from the after-school period is complicated due to a high degree of day-to-day physical activity variability [21, 43]. After school, the children return home from school using various modes of transportation depending on individual routines and the children's after-school activity preferences [5]. Except for PA, after-school time offers a possibility for various other activities, including screenbased sedentary activities and homework [5]. The type and level of after-school PA may have been partially influenced by parental support of PA [26] and their safety-related rules [40].

As for the second objective, we quantified the contribution of active participation in a PEL to the overall daily MVPA in normal-weight and overweight/obese girls and boys. The observed contribution of step count during a PEL in normalweight $(15.8 \%$ \% $15.4 \%$ ) and overweight/obese $(14.2 \%$, $18.1 \%$ ) children to the overall daily MVPA are similar to the results from a study by Tudor-Locke et al. [59]. Although the step count during a PEL in a sample of Czech 9- to 11-year-old boys and girls was similar to children of the same age in California and Arizona [10, 58], the contribution of step count during a PEL to the overall daily MVPA is higher in a sample of Czech children than U.S. children. This difference is due to the finding that the step counts during recesses and after school in the U.S. children were higher than in a sample of Czech children. In contrast to the results of a study by Brusseau et al. [10], no differences were observed in the step count during a PEL between the normal-weight and overweight/obese children. Notably, the step count during a PEL in U.S. children was investigated using spring-levered pedometers that are not designed to directly capture PA intensity [48, 58] and were not equipped with an anti-shock step count filter against excessive shaking.

The monitored PEL attended by Czech children included PA of moderate to high intensity (e.g., dodgeball/floorball; skipping rope; small trampoline jumping). The ActiTrainer triaxial accelerometer consists of three orthogonal accelerometer units and provides a valid estimate of a child's MVPA 
[23]. The temporal pattern of PA in children over days allows the triaxial accelerometers to perform an objective assessment due to the short 15-s monitoring periods [48], which is likely to have caused the contribution of active participation during a PEL to the overall daily MVPA to be greater than the value quantified from the step count in the normal-weight and overweight/obese children.

Regarding objective three, the present study examined the achievement of the current recommendations for MVPA duration during a school day with active participation in a PEL in normal-weight and overweight/obese girls and boys compared to a day without a PEL. While a comparison to other accelerometer-based studies may be difficult due to crosspopulation differences in measurement and procedures [4], the current guideline based on previous research and expert opinions suggest that at least $60 \mathrm{~min}$ MVPA/day is required for youth to have optimal health benefits [14, 15, 27, 63]. In our study, more than $47 \%$ of the overweight/obese girls and normal-weight boys met this recommendation on the school day with active participation in a PEL. In contrast, only $14.3 \%$ of the overweight/obese girls and $30.9 \%$ of the normal-weight boys reached 60 min of MVPA on the day without a PEL.

Previous studies have reported a large variation in the percentage of children reaching the recommended MVPA targets [20]. For example, in a large sample of 11-year-old children in the UK, only $0.9 \%$ of girls and $5.1 \%$ of boys reached at least $60 \mathrm{~min} \mathrm{MVPA/day} \mathrm{[45].} \mathrm{Alternatively,} \mathrm{in} \mathrm{a}$ cohort of 6- to 11-year-old U.S. children, $48.9 \%$ of boys and $34.7 \%$ of girls reached the recommended $60 \mathrm{~min}$ MVPA/day [55]. In terms of MVPA time, our findings of 44.8 and 50.8 (55.1 and 41.9) $\mathrm{min} /$ day for the normal-weight and overweight/obese girls (boys), respectively, are higher than a recent pooled analysis of 20,871 children aged 4-18 years [19] where the published MVPA mean values were $24 \mathrm{~min} /$ day for girls and $37 \mathrm{~min} /$ day for boys [19]. Notably, comparisons of accelerometer-based results have to be interpreted with a certain degree of caution due to the differing decisions by the researchers as to how to capture and process accelerometer data. Longer epoch lengths may under-report MVPA, and differing epoch lengths should not be compared [18].

\section{Limitations and strengths}

The current study has some limitations. The intentional selection of elementary schools requires cautious generalization with respect to the wider population of children in the Czech Republic. In addition, reactivity [46] could have influenced the results, although a 2-weekday pedometer monitoring of school and out-of-school PA in 8- to 14-year-old children has been considered to be non-influential [60]. Currently, not many studies using the ActiTrainer accelerometer in children are published. However, the short period of monitoring (even 1-day monitoring) as opposed to the standard 4- to 5-day monitoring is not unusual $[23,29]$. Previous experience shows that longer monitoring using the ActiTrainer device in children is complicated especially due to the discomfort of wearing the chest belt. Another limitation is the simplified calculation of the maximum age-related heart rate without knowledge of the individual's resting heart rate. Determining the level of body weight using an age-differentiated BMI percentile chart without more accurate knowledge of body composition or current biological age of the children might complicate data interpretation for borderline individuals. The children's body weight and height could be influenced by the measurements performed by their parents as self-reported information about their children [16], but a pairwise comparison of the accelerometer-based MVPA indicators between the school days with and without a PEL was not affected by these potential inaccuracies. A potential source of bias could be the fact that this study did not monitor after school program, which could be an important contributor to the PA of attending children [57]. Other potential confounders could be the socioeconomical status, parental education and other socioenvironmental factors not monitored within the study.

Despite these limitations, the triangulation approach to the measurement of MVPA supports the conclusions of the study. Three simultaneously monitored MVPA indicators (step count, duration, and heart-rate response) from a single ActiTrainer monitoring device provided more reliable results than the results based on a single variable [48]. For a more accurate assessment of the patterns of field-based MVPA using the ActiTrainer monitor, a longer monitoring period [21] (including at least 1 weekend day) during different seasons [45] would be needed. A more comprehensive understanding of MVPA in school-aged children also requires valid information as to the possible influence of lifestyle behaviour, parents, peer support, and the environmental characteristics of their residence.

\section{Conclusion}

A global increase in obesity in school-age children along with a decrease in their PA provide reasons to continue the search for effective strategies that could increase MVPA and subsequently reduce the incidence of childhood obesity. Schools offer an optimal environment for designing, implementing, and evaluating interventions for all school-aged children. This study presents evidence that active participation in PEL contributes to a significantly higher step count, MVPA duration, and heart-rate response during school MVPA in normalweight and overweight/obese boys $(p<0.001)$ and normalweight $(p<0.001)$ and overweight/obese $(p<0.04)$ girls. Moreover, active participation in PEL significantly $(p<0.04)$ increases the overall daily step count, MVPA duration, and MVPA heart-rate response in normal-weight boys and 
overweight/obese girls. Adding one PEL or an equivalent amount of MVPA to the daily school routine appears to be a promising strategy to effectively increase daily MVPA, particularly among overweight/obese girls.

Acknowledgements The authors are grateful to the 338 children and their families who participated in this study. Exceptional thanks go to all teachers and school management members for school childcare. This paper was supported by the ECOP project "Strengthening scientific potential of the research teams in promoting physical activity at Palacky University" reg. No. CZ.1.07/2.3.00/20.0171, research grant from Faculty of Physical Culture, Palacky University in Olomouc "Family Environment as a Correlate of Physical Activity 6-12 years old children" reg. no. FTK 2013:006.

Conflict of interest The authors declare that they have no conflict of interests.

Open Access This article is distributed under the terms of the Creative Commons Attribution License which permits any use, distribution, and reproduction in any medium, provided the original author(s) and the source are credited.

\section{References}

1. Adamo KB, Prince SA, Tricco AC, Connor-Gorber S, Tremblay M (2009) A comparison of indirect versus direct measures for assessing physical activity in the pediatric population: a systematic review. Int J Pediatr Obes 4:2-27. doi:10.1080/17477160802315010

2. Armstrong N (1998) Young people's physical activity patterns as assessed by heart rate monitoring. J Sports Sci 16:S9-S16. doi:10. 1080/026404198366632

3. Armstrong N, Balding J, Gentle P, Kirby B (1990) Patterns of physical activity among 11 to 16 year old British children. Br Med J 301:203-205

4. Armstrong N, Welsman JR (2006) The physical activity patterns of European youth with reference to methods of assessment. Sports Med 36:1067-1086

5. Atkin AJ, Gorely T, Biddle SHJ, Marshall SJ, Cameron N (2008) Critical hours: physical activity and sedentary behaviour of adolescents after school. Pediatr Exerc Sci 20:446-456

6. Bailey DP, Fairclough SJ, Savory LA, Denton SJ, Pang D, Deane CS, Kerr CJ (2012) Accelerometry-assessed sedentary behaviour and physical activity levels during the segmented school day in 10-14year-old children: the HAPPY study. Eur J Pediatr 171:1805-1813. doi:10.1007/s00431-012-1827-0

7. Bassett DR (2012) Device-based monitoring in physical activity and public health research. Physiol Meas 33:1769-1783. doi:10.1088/ 0967-3334/33/11/1769

8. Brage S, Brage N, Franks PW, Ekelund U, Wong MY, Andersen LB, Froberg K, Wareham NJ (2004) Branched equation modelling of simultaneous accelerometry and heart rate monitoring improves estimate of directly measured physical activity energy expenditure. $\mathrm{J}$ Appl Physiol 96:343-351. doi:10.1152/japplphysiol.00703.2003

9. Branca F, Nikogosian H, Lobstein T (eds) (2007) The challenge of obesity in the WHO European Region and the strategies for response: summary. WHO Regional Office for Europe, Copenhagen

10. Brusseau TA, Kulinna PH, Tudor-Locke C, Ferry M, van der Mars H, Darst PW (2011) Pedometer-determined segmented physical activity patterns of fourth- and fifth-grade children. J Phys Act Health 8:279-286

11. Cohen J (1988) Statistical power analysis for the behavioural sciences, 2nd edn. Erlbaum, Hillsdale
12. Cortina JM, Nouri H (2000) Effect size for ANOVA design, 1st edn. Sage publications, Thousand Oaks

13. Czech Statistical Office (2010) Statistical yearbook of the Czech Republic 2010. Scientia, Prague

14. Department of Health and Human Services (2010) Healthy People 2020. http://www.cdc.gov/nchs/healthy_people/hp2020.htm. Accessed 18 April 2013

15. Department of Health, Social Services and Public Safety (2011) Start Active, Stay Active: a report on physical activity for health from the four home countries' Chief Medical Officers. http://www.bhfactive. org.uk/userfiles/Documents/startactivestayactive.pdf. Accessed 18 April 2013

16. Eckstein KC, Mikhail LM, Ariza AJ, Thomson JS, Millard SC, Binns HJ (2006) Parents' perception of their child's weight and health. Pediatric 117:681-690. doi:10.1542/peds.2005-0910

17. Edwards S (2010) The heart rate monitor guidebook to heart zone training, 5th edn. Velopress, Sacramento

18. Edwardson CL, Gorely T (2010) Epoch length and its effect on physical activity intensity. Med Sci Sports Exerc 42:928-934. doi: 10.1249/MSS.0b013e3181c301f5

19. Ekelund U, Luan J, Sherar LB, Esliger DW, Griew P, Cooper A (2012) Moderate to vigorous physical activity and sedentary time and cardiometabolic risk factors in children and adolescents. J Am Med Assoc 307:704-712

20. Ekelund U, Tomkinson GR, Armstrong N (2011) What proportion of youth are physically active? Measurement issues, levels and recent time trends. Br J Sports Med 45:859-865. doi:10.1136/bjsports2011-090190

21. Fairclough SJ, Butcher ZH, Stratton G (2007) Whole-day and segmented-day physical activity variability of northwest England school children. Prev Med 44:421-425. doi:10.1016/j.ypmed.2007.01.002

22. Fairclough SJ, Beighle A, Ervin H, Ridgers ND (2012) School day segmented physical activity patterns of high and low active children. BMC Public Health 12:406. doi:10.1186/1471-2458-12-406

23. Groffik D, Sigmund E, Frömel K, Chmelík F, Nováková Lokvencová P (2012) The contribution of school breaks to the all-day physical activity of 9- and 10-year-old overweight and non-overweight children. Int J Public Health 57:711-718. doi:10.1007/s00038-012-0355-Z

24. Hallal PC, Andersen LB, Bull FC, Guthold R, Haskell W, Ekelund U (2012) Global physical activity levels: surveillance progress, pitfalls, and prospects. Lancet 18:20-30. doi:10.1016/S0140-6736(12) 60646-1

25. Herman KM, Craig CL, Gauvin L, Katzmarzyk PT (2009) Tracking of obesity and physical activity from childhood to adulthood: the Physical Activity Longitudinal Study. Int J Pediatr Obes 4:281-288. doi:10.3109/17477160802596171

26. Hohepa M, Scragg R, Schofield G, Kolt GS, Schaaf D (2007) Social support for youth physical activity: importance of siblings, parents, friends and school support across a segmented school day. Int $\mathrm{J}$ Behav Nutr Phys Act 4:54. doi:10.1186/1479-5868-4-54

27. Janssen I, LeBlanc AG (2010) Systematic review of the health benefits of physical activity and fitness in school-aged children and youth. Int J Behav Nutr Phys Act 7:40. doi:10.1186/1479-5868-7-40

28. Jansen W, Borsboom G, Meina A, van Zwanenburg EJ, Mackenbach JP, Raat H, Brug J (2011) Effectiveness of a primary school-based intervention to reduce overweight. Int J Pediatr Obes 6:70-77. doi: $10.3109 / 17477166.2011 .575151$

29. Janssen M, Toussaint H, Van Willem M, Verhagen E (2011) PLAYgrounds: effect of a PE playground program in primary schools on PA levels during recess in 6 to 12 year old children. Design of a prospective controlled trial. BMC Public Health 11:282

30. Kalman M, Sigmund E, Sigmundová D, Hamř́k Z, Beneš L, Benešová D, Csémy L (2011) Národní zpráva o zdraví a životním stylu dětí a školáků, 1st edn [National report of health and lifestyle of schoolchildren]. Vydavatelství Univerzity Palackého v Olomouci, Olomouc 
31. Kersh R, Stroup DF, Taylor WC (2011) Childhood obesity: a framework for policy approaches and ethical considerations. Prev Chronic Dis $8: 1-5$

32. Khambalia AZ, Dickinson S, Hardy LL, Gill T, Baur LA (2012) A synthesis of existing systematic reviews and meta-analyses of schoolbased behavioural intervention for controlling and preventiv obesity. Obes Rev 13:214-233. doi:10.1111/j.1467-789X.2011.00947.x

33. Kirkpatrick B, Birnbaum BH (1997) Lessons from the heart: individualizing physical education with heart rate monitors, 1st edn. Human Kinetics, Champaign

34. Kriemler S, Meyer U, Martin E, van Sluijs EMF, Andersen LB, Martin BW (2011) Effect of school-based intervention on physical activity and fitness in children and adolescents: a review of reviews and systematic update. Br J Sports Med 45:923-930. doi:10.1136/ bjsports-2011-090186

35. Lavelle HV, Mackay DF, Pell JP (2012) Systematic review and metaanalysis of school-based intervention to reduce body mass index. $\mathrm{J}$ Public Health 116:1-10. doi:10.1093/pubmed/fdr116

36. Mallam KM, Metcalf BS, Kirkby J, Voss DL, Wilkin TJ (2003) Contribution of timetabled physical education to total physical activity in primary school children: cross sectional study. Brit Med J (Int Ed) 327:592-593

37. McNamara E, Hudson Z, Taylor SJC (2010) Measuring aktivity levels of young people: the validity of pedometers. Br Med Bull 95:121-137. doi:10.1093/bmb/ldq016

38. Michalopoulou M, Gourgoulis V, Kourtessis T, Kambas A, Dimitrou M, Gretziou H (2011) Step counts and body mass index among 9-14 years old Greek schoolchildren. J Sports Sci Med 10: 215-221

39. Neuls F (2008) Validity and reliability of "step count" function of the ActiTrainer activity monitor under controlled conditions. Acta Univ Palacki Olomuc Gymn 38:55-64

40. Nichol M, Janssen I, Pickett W (2010) Associations between neighborhood safety, availability of recreational facilities, and adolescent physical aktivity among Canadian youth. J Phys Act Health 7:442-450

41. Ogden CL, Carroll MD, Kit BK, Flegal KM (2012) Prevalence of obesity and trends in body mass index among US children and adolescents, 1999-2010. J Am Med Assoc 305:483-490. doi:10. 1001/jama.2012.40

42. Olds T, Maher C, Zumin S, Péneau S, Lioret S, Castetbon K, Bellisle F, Wilde DJ, Hohepa M, Maddison R, Lissner L, Sjöberg A, Zimmermann M, Aeberli I, Ogden C, Flegal K, Summerbell C (2011) Evidence that the prevalence of childhood overweight is plateauing: data from nine countries. Int J Pediatr Obes 6:342-360. doi:10.3109/17477166.2011.605895

43. Page A, Cooper AR, Stamatakis E, Foster LJ, Crowne EC, Sabin M, Shield JPH (2005) Physical activity patterns in nonobese and obese children assessed using minute-by-minute accelerometry. Int J Obes 29:1070-1076. doi:10.1038/sj.ijo.0802993

44. Resaland GK, Andersen LB, Mamen A, Andersen SA (2011) Effects of a 2-year school-based daily physical activity intervention on cardiorespiratory fitness: the Sogndal school-intervention study. Scan J Med Sci Sports 21:302-309. doi:10.1111/j.1600-0838.2009.01028.x

45. Riddoch CJ, Mattocks C, Deere K, Saunders J, Kirkby J, Tilling K, Leary SD, Ness AR, Blair SN (2007) Objective measurement of levels and patterns of physical activity. Arch Dis Child 92:963-969. doi:10.1136/adc.2006.112136

46. Rowe DA, Mahar MT, Raedeke TD, Lore J (2004) Measuring physical activity in children with pedometers: reliability, reactivity, and replacement of missing data. Pediatr Exerc Sci 16:343-354
47. Rowlands AV (2007) Accelerometer assessment of physical activity in children: an update. Pediatr Exerc Sci 19:252-266

48. Rowlands AV, Eston RG (2007) The measurement and interpretation of children's physical activity. J Sports Sci Med 6:270-276

49. Sigmund E, El Ansari W, Sigmundová D (2012) Does school-based physical activity decrease overweight and obesity in children 69 years? A two-year non-randomized longitudinal intervention study in the Czech Republic. BMC Public Health 12:570. doi:10.1186/ 1471-2458-12-570

50. Sigmundová D, El Ansari W, Sigmund E, Frömel K (2011) Secular trends: a ten-year comparison of the amount and type of physical activity and inactivity of random samples of adolescents in the Czech Republic. BMC Public Health 11:731. doi:10.1186/1471-2458-11-731

51. Sigmundová D, Sigmund E, Hamrik Z, Kalman M (2013) Trends of overweight and obesity, physical activity and sedentary behaviour in Czech schoolchildren: HBSC study. Eur J Public Health. doi:10. 1093/eurpub/ckt085

52. Steele RM, van Sluijs EMF, Cassidy A, Griffin SJ, Ekelund U (2009) Targeting sedentary time or moderate- and vigorous-intensity activity: independent relations with adiposity in a population-based sample of 10-y-old British children. Am J Clin Nutr 90:1185-1192. doi: 10.3945/ajen.2009.28153

53. Telama R (2009) Tracking of physical activity from childhood to adulthood: a review. Obes Facts 2:187-195. doi:10.1159/000222244

54. Thomas JR, Nelson JK (2001) Research methods in physical activity, 4th edn. Human Kinetics, Champaign

55. Troiano RP, Berrigan D, Dodd KW, Mâsse LC, Tilert T, McDowell M (2008) Physical activity in the United States measured by accelerometer. Med Sci Sports Exerc 40:181-188. doi:10.1249/mss. 0b013e31815a51b3

56. Trost SG, Loprinzi PD, Moore R, Pfeiffer KA (2011) Comparison of accelerometer cut points for predicting activity intensity in youth. Med Sci Sports Exerc 43:1360-1368. doi:10.1249/MSS. 0b013e318206476e

57. Trost SG, Rosenkranz RR, Dzewaltowski D (2008) Physical activity levels among children attending after-school programs. Med Sci Sports Exerc 40:622-629. doi:10.1249/MSS.0b013e318161 eaa5

58. Tudor-Locke C, Lee SM, Morgan CF, Beighle A (2006) Children's pedometer-determined physical activity during the segmented school day. Med Sci Sports Exerc 38:1732-1738. doi:10.1249/01.mss. 0000230212.55119 .98

59. Tudor-Locke C, McClain JJ, Hart TL, Sisson SB, Washington TL (2009) Expected values for pedometer-determined physical activity in youth. Res Q Exerc Sport 80:164-174

60. Tudor-Locke C, McClain JJ, Hart TL, Sisson SB, Washington TL, Tracy L (2009) Pedometry methods for assessing free-living youth. Res Q Exerc Sport 80:175-184

61. Vignerová J, Humeníkova L, Brabec M, Riedlová J, Bláha P (2007) Long-term changes in body weight, BMI, and adiposity rebound among children and adolescents in the Czech republic. Econ Hum Biol 5:409-425. doi:10.1016/j.ehb.2007.07.003

62. World Health Organization (2007) Growth reference data for 519 years. WHO Reference 2007. http://www.who.int/growthref/en/. Accessed 18 April 2013

63. World Health Organization (2010) Global recommendations on physical activity for health. http://www.who.int/dietphysicalactivity/ factsheet recommendations/en/. Accessed 18 April 2013

64. Yang CC, Hsu YL (2010) A review of accelerometry-based wearable motion detectors for physical activity monitoring. Sensors 10:77727788. doi: $10.3390 / \mathrm{s} 100807772$ 